\title{
Esthetical treatments. National Academy of Medicine of Mexico position
}

\author{
Armando Mansilla-Olivares, José Ignacio Santos-Preciado, Ricardo Plancarte-Sánchez, \\ Fernando Meneses-González, Fermín Valenzuela-Gómez-Gallardo, Joaquín López-Bárcena and \\ Gilberto Felipe Vázquez-De Anda \\ Academia Nacional de Medicina de México, Committee of Liaison and Dissemination of Knowledge, Ciudad de México, Mexico
}

\begin{abstract}
In Mexico there is a proliferation of "centers for aesthetic medicine" that offer different treatments with laser beam, mesotherapy and hyaluronic acid and botulinum toxin injections. In numerous centers of this type, offered and performed by medical personnel that are neither trained or certified to ensure the quality of services. The National Academy of Medicine of Mexico and the National Normative Council for Medical Specialties (CONACEM) communicate their posture on this matter.
\end{abstract}

KEY WORDS: Aesthetic medicine. Mesotherapy. Laser beam treatment. Hyaluronic acid. Botulinum toxin.

Personal interest on maintaining or improving esthetical appearance has promoted for specialized offer for the provision of medical services of plastic, esthetic and reconstructive surgery to grow to such a degree that, currently, "esthetic centers" without support from a certified specialist in the area offer medical treatments with laser beam (spots, varices, tattoos), mesotherapy, hyaluronic acid or botulinum toxin application, without medical guarantee or legal certainty to support the quality of the intervention or the used treatments. These centers, where non-scientifically-approved esthetic medicine treatments are marketed and that carry out deceptive advertising practices, are usually managed by general practitioners who hold titles of non-approved esthetic medicine courses or Master's Degrees in Esthetic Surgery that lack the support and recognition of institutions such as the National Academy of Medicine of Mexico or the National Academy of Surgery of the National Normative Committee of Medical Specialty Councils (CONACEM - Comité Normativo Nacional de Consejos de Especialidades Médicas), which confer suitability and thereby certainty about the specialist's professional training, as to exercise his/her knowledge on his/her daily professional practice.
Simultaneously, a series of courses have appeared at different states of the Republic that offer Master's degrees or different specialties in esthetics that, as above mentioned, lack the corresponding certification and whose graduates therefore lack medical knowledge, surgical skills and the necessary aptitudes to offer the patient and his/her relatives the scientific safety and quality of the knowledge that is exercised on the patient. Thus, these courses should not stay aloof from the Single Program for Medical Specialties (PUEM - Programa Único de Especialidades Médicas), which all officially recognized higher education institutions must be subjected to in order to be able to grant a specialist, master's degree or doctorate diploma, according to article 81 , first and second paragraphs, of the General Statute of Health.

Notwithstanding the above, there are some education centers, particularly in the state of Veracruz, that offer plans and study programs with official recognition by the Ministry of Education of said state and, according to its official validity of studies recognition, one of these centers in particular is authorized to offer academic degrees of specialty or MSc in esthetics. However, regardless of the above, the courses are not full-time and they are taken face-to-face on Saturdays and online on business days. Therefore, although the
Correspondence:

Armando Mansilla-Olivares

E-mail: armanolnc@gmail.com
Date of reception: 12-10-2018

Date of acceptance: 23-10-2018

DOI: 10.24875/GMM.M19000221
Gac Med Mex. 2018;154:635-636

Contents available at PubMed www.gacetamedicademexico.com 
master's degree allows them to practice research or teaching activities, it does not authorize them to practice as specialists in clinical practice and much less in surgical practice. For this reason, on January 18, 2017, the National Council of Medical Specialties A.C. denied the authorization for graduates of that center to take the certification exam at the Mexican Council of Plastic, Esthetic and Reconstructive Surgery, A.C.

There is a civil association, the denomination of which is Mexican Council of Certification in Esthetic Medicine, which is not recognized by CONACEM, and therefore it lacks powers for accreditation of third parties, regardless of the document apparently granted by public notary 211 of the Federal District in book 1,507, title 62,054 , on January 29,2013 . This association was set up, as well as the Mexican Society of Esthetic Medicine, Nutrition, Anti-aging and Homotoxicology, A.C., by the same person who apparently runs the Institute of Higher Studies in Medicine, S.C. For the above, this council is completely alien to CONACEM, to the National Academy of Medicine of Mexico and to the Mexican Academy of Surgery.

Given the importance this has for public health and scientific advance in our country and in view of the appearance of this type of associations outside the regulatory framework, the National Academy of Medicine of Mexico, as an advisory body of the federal government and with the power granted by the tripartite chair of the National Council of Academies, establishes the following recitals:
- In medical science there is no such thing as esthetic surgery, since esthetic treatments are noninvasive and a surgical procedure is therefore not required for their application; in fact, esthetic procedures are based on products of cosmetic nature.

- In the context of plastic surgery or reconstructive surgery, esthetic procedures are subsumed, but cannot be separated if treatment is invasive; therefore the specialty is named Plastic, Esthetic and Reconstructive Surgery. Consequently, esthetic surgery only occurs when it is accessory to a plastic or reconstructive surgery.

- Based on the foregoing, the National Academy of Medicine of Mexico, in line with the position of CONACEM, an auxiliary body of federal public administration, informs that the Mexican Council of Certification in Esthetic Medicine, A.C. does not comply with article 81 , third paragraph, of the General Statute of Health, and alerts the medical community and society in general about the deception to the population of this type of associations, which frustrate young people expectations and incur non-observance of the law, eliciting different types of iatrogenesis and injuries that endanger the lives of those who undergo this type of treatment, when placing their trust in non-certified personnel as regards their knowledge and skills. 